Check for updates

Cite this: RSC Adv., 2019, 9, 450

Received 29th September 2018 Accepted 23rd November 2018

DOI: $10.1039 / c 8 \mathrm{ra0} 0085 \mathrm{~b}$

rsc.li/rsc-advances

\section{Employing a novel $\mathrm{O}_{3} / \mathrm{H}_{2} \mathrm{O}_{2}+\mathrm{BiPO}_{4} / \mathrm{UV}$ synergy technique to deal with thiourea-containing photovoltaic wastewater $\dagger$}

\author{
Zhikai Wei, Peng Li, Muhammad Hassan, Pu Wang, Cong Xu, Long-Fei Ren \\ and Yiliang $\mathrm{He}$ (iD *
}

Photovoltaic wastewater contains a large amount of thiourea that cannot be directly treated by biological methods because of its biotoxicity. In this study, a novel $\mathrm{O}_{3} / \mathrm{H}_{2} \mathrm{O}_{2}+\mathrm{BiPO}_{4} / \mathrm{UV}$ synergy technique was used as a pre-treatment process to degrade thiourea. The effects of $\mathrm{H}_{2} \mathrm{O}_{2}$ and catalyst loading were investigated, and the transformation pathway of thiourea was predicted based on the intermediates detected by UPLCVion-IMS-QToF. The synergy technique degraded $89.14 \%$ thiourea within only $30 \mathrm{~min}$, and complete degradation occurred after 150 min. The TOC removal of $\mathrm{O}_{3} / \mathrm{H}_{2} \mathrm{O}_{2}+\mathrm{BiPO}_{4} / \mathrm{UV}$ was 1.8, 1.5, and 1.9 times that of $\mathrm{O}_{3} / \mathrm{H}_{2} \mathrm{O}_{2}$ and $\mathrm{BiPO}_{4} / U V / \mathrm{H}_{2} \mathrm{O}_{2}$ single processes and $\mathrm{O}_{3} / \mathrm{H}_{2} \mathrm{O}_{2}+\mathrm{UV}$ process, respectively, which was due to the synergy between $\mathrm{H}_{2} \mathrm{O}_{2}$ residues and $\mathrm{BiPO}_{4}$. In addition, thiourea was mainly degraded by $\cdot \mathrm{OH}$ into thiourea dioxide and melamine (polymerized by other intermediates) and then further degraded into biuret and methyl carbamate by the holes of $\mathrm{BiPO}_{4}$, followed by complete mineralization into $\mathrm{H}_{2} \mathrm{O}$ and $\mathrm{CO}_{2}$. These results confirm that the $\mathrm{O}_{3} / \mathrm{H}_{2} \mathrm{O}_{2}+\mathrm{BiPO}_{4} / U V$ synergy technique is a promising option for the degradation of thiourea.

\section{Introduction}

Thiourea is widely used in numerous industries, ${ }^{\mathbf{1 - 4}}$ especially in the photovoltaic industry. It is used in chemical bath deposition to produce CdS polycrystalline films for thin-film solar cells. ${ }^{5}$ Hence, wastewater from photovoltaic plants contains a large amount of redundant thiourea. It degrades slowly in the natural environment and has serious effects on human health. ${ }^{6-8}$ Due to the biological toxicity of thiourea, ${ }^{9}$ it cannot be treated directly by biological methods. Advanced oxidation processes (AOPs) can be an alternative method for the pre-treatment of photovoltaic wastewater containing high concentration of thiourea, transforming thiourea into other substances without biotoxicity.

Considering that photovoltaic wastewater contains high concentrations of organic matter and salts, the process we use cannot further introduce excess salt as it will be overdischarged. An $\mathrm{O}_{3} / \mathrm{H}_{2} \mathrm{O}_{2}$ Fenton-like process was selected as it generates extraordinarily reactive hydroxyl radicals $(\cdot \mathrm{OH})$ by the reaction of ozone and hydrogen peroxide without salt introduction. These radicals subsequently attack and decompose contaminants in the water, and the process is usually effective,

School of Environmental Science and Engineering, Shanghai Jiao Tong University, 800 Dongchuan Road, 200240 Shanghai, PR China. E-mail: ylhe@sjtu.edu.cn; Tel: +86 21-54744008

† Electronic supplementary information (ESI) available. See DOI: 10.1039/c8ra08085b simple, environment-friendly and economically sustainable. The $\mathrm{O}_{3} / \mathrm{H}_{2} \mathrm{O}_{2}$ method enables rapid degradation of various recalcitrant organic compounds such as perfluorinated chemicals, dibutylsulfide, dimethyl sulfoxide, phenol and linear alkyl benzene. ${ }^{10-14}$ However, using $\mathrm{H}_{2} \mathrm{O}_{2}$ alone in the $\mathrm{O}_{3} / \mathrm{H}_{2} \mathrm{O}_{2}$ process is not sufficient as excess $\mathrm{H}_{2} \mathrm{O}_{2}$ residues not only affect the degradation efficiency but also increase COD of the water sample and affect the post-treatment process. ${ }^{15}$

Some studies have improved the utilization efficiency of $\mathrm{H}_{2} \mathrm{O}_{2}$ residues by employing photo-irradiation. ${ }^{16}$ Nevertheless, - $\mathrm{OH}$ generated by $\mathrm{UV}$ or $\mathrm{O}_{3} / \mathrm{H}_{2} \mathrm{O}_{2}$ is inferior in organic mineralization as $\cdot \mathrm{OH}$ tends to abstract hydrogen from $\mathrm{C}-\mathrm{H}$ bonds or add hydrogen to unsaturated carbon-sulfur bonds; if these bonds are not present (e.g., oxalic acid, which is one of the intermediates in the degradation of phenol ${ }^{17}$ ), the oxidation ability of $\cdot \mathrm{OH}$ will be limited. A photocatalyst, namely, bismuth phosphate $\left(\mathrm{BiPO}_{4}\right)$ is considered an alternative as it can generate holes, which enhance the mineralization efficiency. It has been proven to be an efficient catalyst and has an optical indirect band gap of $3.85 \mathrm{eV}$. The photocatalytic activity of $\mathrm{BiPO}_{4}$ is twice that of titanium dioxide $\left(\mathrm{TiO}_{2} \mathrm{P} 25\right.$, Degussa). ${ }^{18}$ $\mathrm{BiPO}_{4}$ possesses excellent photocatalytic activity due to the inductive effect of $\mathrm{PO}_{4}{ }^{3-}$ since it can separate electrons and holes. $\mathrm{BiPO}_{4}$ has been applied for the removal of dyes ${ }^{\mathbf{1 8}}$ and phenols. ${ }^{19} \mathrm{BiPO}_{4}$ not only improves the mineralization efficiency but also has a synergistic effect with $\mathrm{H}_{2} \mathrm{O}_{2}$. In a previous study, $\mathrm{BiPO}_{4}$ coupled with $60 \mathrm{mg} \mathrm{L}^{-1} \quad \mathrm{H}_{2} \mathrm{O}_{2}$ significantly improved the degradation efficiency of phenol ${ }^{20}$. Adequate $\mathrm{H}_{2} \mathrm{O}_{2}$ 
interacted with $\mathrm{BiPO}_{4}$, improving the photocatalytic efficiency of $\mathrm{BiPO}_{4}$ by increasing the separation efficiency of $\mathrm{e}^{-}$and $\mathrm{h}^{+}$ through the capture of $\mathrm{e}^{-}$by $\mathrm{H}_{2} \mathrm{O}_{2}$. Based on these facts, the $\mathrm{O}_{3} /$ $\mathrm{H}_{2} \mathrm{O}_{2}+\mathrm{BiPO}_{4} / \mathrm{UV}$ synergy technique was developed in this study. We hypothesize that $\mathrm{H}_{2} \mathrm{O}_{2}$ residues after $\mathrm{O}_{3} / \mathrm{H}_{2} \mathrm{O}_{2}$ treatment will be utilized by $\mathrm{BiPO}_{4} / \mathrm{UV}$, which is a novel approach.

In this study, we report the improvement in thiourea transformation efficiency and TOC removal by using the $\mathrm{O}_{3} / \mathrm{H}_{2} \mathrm{O}_{2}+$ $\mathrm{BiPO}_{4} / \mathrm{UV}$ synergy technique coupled with the investigation of the utilization efficiency of residual $\mathrm{H}_{2} \mathrm{O}_{2}$. We have also investigated the effects of $\mathrm{H}_{2} \mathrm{O}_{2}$ concentration and catalyst loading. The possible transformation pathway of thiourea is predicted in the end.

\section{Material and methods}

\subsection{Solution preparation}

Synthetic solutions were prepared using $18.2 \mathrm{M} \Omega \mathrm{cm}$ Milli-Q deionized water. All the reagents used were of analytical grade. Thiourea was supplied by Aladdin (USA), ammonium chloride by Sinopharm Chemical reagent Co., Ltd. (China) and hydrogen peroxide $(30 \% \mathrm{w} / \mathrm{v})$ by Macklin (USA). For residual $\mathrm{H}_{2} \mathrm{O}_{2}$ test, potassium titanyl oxalate was purchased from Macklin (USA). Thiourea (1.2 g) and ammonium chloride (0.535 $\mathrm{g}$ ) (as the source of ammonium nitrogen) were added into $1 \mathrm{~L}$ of deionized distilled water to simulate photovoltaic wastewater.

\subsection{Preparation of $\mathrm{BiPO}_{4}$}

$\mathrm{BiPO}_{4}$ nanorods were prepared via the reflux method. ${ }^{21}$ In short, $1.956 \mathrm{~g}$ of $\mathrm{Bi}\left(\mathrm{NO}_{3}\right)_{3} \cdot 5 \mathrm{H}_{2} \mathrm{O}$ (AR, Macklin) and $3.145 \mathrm{~g}$ of $\mathrm{NaH}_{2}-$ $\mathrm{PO}_{4} \cdot 2 \mathrm{H}_{2} \mathrm{O}$ (AR, Macklin) were added into a flask, followed by mixing with at least $750 \mathrm{~mL}$ of deionized water. After the $\mathrm{pH}$ was adjusted to 2.2 with concentrated nitric acid (Sinopharm Chemical reagent Co., Ltd.), the flask was placed in an oil bath $\left(120^{\circ} \mathrm{C}\right)$ and mixing was conducted at $800 \mathrm{rpm}$, followed by heating for 48 hours. The resultant white precipitate was washed three times with deionized water and dried at $120^{\circ} \mathrm{C}$ for 12 hours.

\subsection{Experimental set-up and procedure}

2.3.1 Experimental set-up. A self-designed experimental setup was employed in this study, as shown in Fig. 1. Ozone was generated using a laboratory ozone generator having a maximum generation capability of $32 \mathrm{~g} \mathrm{~h}^{-1}$. The flow rate was adjusted to $5 \mathrm{~L} \mathrm{~min}^{-1}$ before inserting into the ozone reaction tower. The volume of the ozone reaction tower was $12 \mathrm{~L}$. To fully mix the gas and liquid phases, a reflux unit was used in the ozone reaction tower with a reflux rate of $2 \mathrm{~L} \mathrm{~min}^{-1}$. The reflux unit was equipped with a $\mathrm{pH}$ meter and a dosing pump to monitor the $\mathrm{pH}$ variation and $\mathrm{H}_{2} \mathrm{O}_{2}$. After $\mathrm{O}_{3} / \mathrm{H}_{2} \mathrm{O}_{2}$ treatment, samples were transferred into a photo reactor. The photo reactor included two low-pressure mercury lamps $(254 \mathrm{~nm}$, $11 \mathrm{~W}$, Philips, China) housed inside a wooden box. The intensity of UV irradiation was $4.73 \mathrm{~mW} \mathrm{~cm}^{-2}$, measured by an ultraviolet radiation meter (UV-C, photoelectric instrument factory of Beijing Normal University, China). The Petri factor for the lowpressure UV system was determined to be greater than 0.9.

\subsubsection{Experimental procedure}

$\mathrm{O}_{3} / \mathrm{H}_{2} \mathrm{O}_{2}+\mathrm{BiPO}_{4} / \mathrm{UV}$ synergy technique. $\mathrm{O}_{3} / \mathrm{H}_{2} \mathrm{O}_{2}+\mathrm{BiPO}_{4} / \mathrm{UV}$ synergy technique was carried out in the self-designed setup (Fig. 1). The optimum conditions for maximizing the TOC residues and specifying the hydrogen peroxide residues of $\mathrm{O}_{3} /$ $\mathrm{H}_{2} \mathrm{O}_{2}$ treatment were determined by means of a three-factor three-level Box-Behnken experimental design (BBD) combined with the response surface methodology (RSM) to correlate experimentally obtained criteria and experimental conditions given by the Box-Behnken experimental design. The independent variables were the initial concentrations of $\mathrm{H}_{2} \mathrm{O}_{2}\left(X_{1}\right)$ and

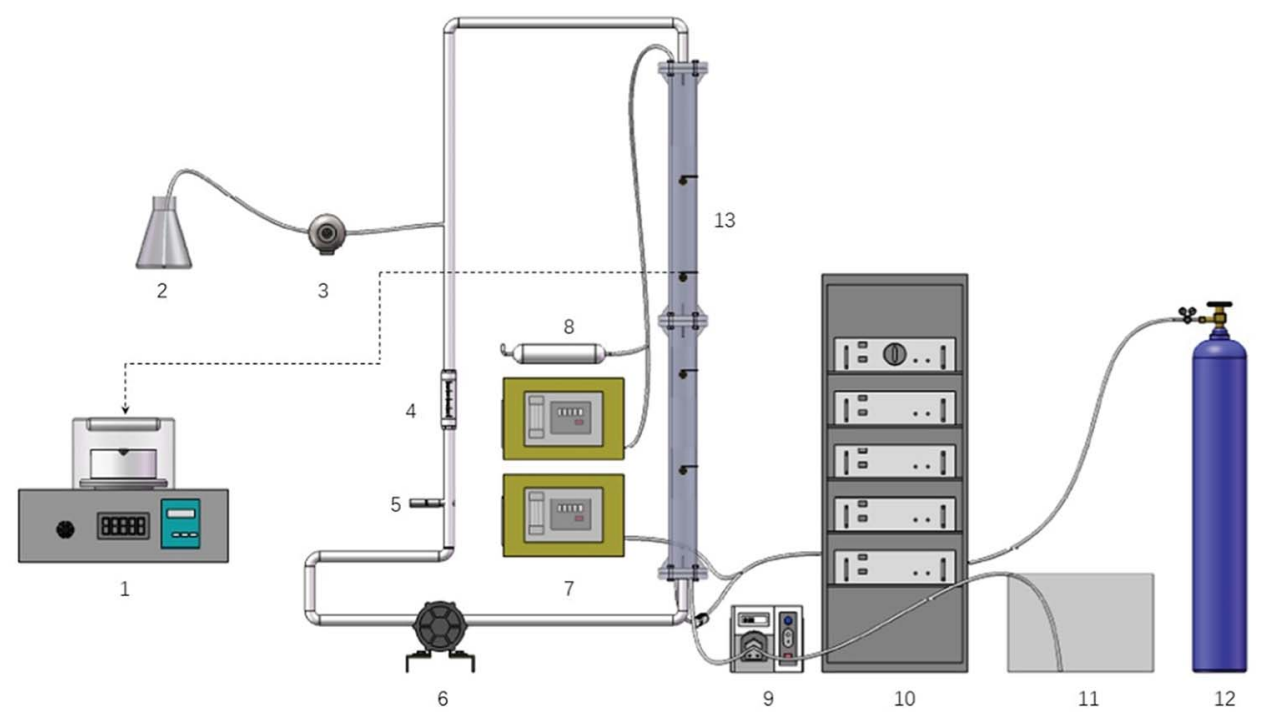

Fig. 1 Experiment reactor. (1): Photoreactor instrument; (2): agents can for $\mathrm{H}_{2} \mathrm{O}_{2}$; (3): agents pump; (4): flowmeter; (5): $\mathrm{pH}$-meter; (6): circulating pump; (7): ozone meter; (8): ozone destructor; (9): peristaltic pump; (10): ozonator; (11): wastewater tank; (12): oxygen bottle; (13): reaction tower. 
Table 1 Independent variables and their coded levels based on the Box-Behnken design

\begin{tabular}{lcrrr}
\hline & & \multicolumn{2}{l}{ Code levels } \\
\cline { 3 - 5 } $\begin{array}{l}\text { Independent } \\
\text { variable }\end{array}$ & Symbol & \multicolumn{1}{c}{-1} & 0 & 1 \\
\hline $\mathrm{H}_{2} \mathrm{O}_{2}(\mathrm{~mL})$ & $X_{1}$ & 10 & 45 & 80 \\
$\mathrm{O}_{3}\left(\mathrm{mg} \mathrm{L}^{-1}\right)$ & $X_{2}$ & 20 & 50 & 80 \\
$\mathrm{pH}$ & $X_{3}$ & 4 & 7 & 10
\end{tabular}

$\mathrm{O}_{3}\left(X_{2}\right)$ and the initial $\mathrm{pH}\left(X_{3}\right)$, which were coded as $-1,0$ and +1 , as shown in Table 1 .

The total number of experimental trials was 17 based on a three level and a three factor experimental design with three replicates at the centre of the design to estimate a pure error sum of squares. TOC residues, $\mathrm{H}_{2} \mathrm{O}_{2}$ residues and the 'pseudo'-second order rate constant were considered as dependent factors (process responses). Specific experimental conditions of the $\mathrm{O}_{3} / \mathrm{H}_{2} \mathrm{O}_{2}$ treatment were selected according to the reaction model generated by BBD. The experimental conditions could achieve the desired reaction results of the $\mathrm{O}_{3} / \mathrm{H}_{2} \mathrm{O}_{2}$ treatment process. After 150 min of the $\mathrm{O}_{3} / \mathrm{H}_{2} \mathrm{O}_{2}$ treatment, the treated effluent $(100 \mathrm{~mL})$ was transferred into a low-pressure (LP) UV collimated beam system with a specific amount of $\mathrm{BiPO}_{4}$ after stirring and ultrasonicating for $10 \mathrm{~min}$ before irradiation. The $\mathrm{UV}$ intensity was $4.73 \mathrm{~mW} \mathrm{~cm}{ }^{-2}$ in average and the $\mathrm{BiPO}_{4} / \mathrm{UV}$ post-treatment lasted for 180 minutes.

$\mathrm{O}_{3} / \mathrm{H}_{2} \mathrm{O}_{2}+\mathrm{UV}$ process. The experimental procedure of the $\mathrm{O}_{3} /$ $\mathrm{H}_{2} \mathrm{O}_{2}+\mathrm{UV}$ process was similar to that of the $\mathrm{O}_{3} / \mathrm{H}_{2} \mathrm{O}_{2}+\mathrm{BiPO}_{4} /$ UV synergy technique. Experimental conditions of the $\mathrm{O}_{3} / \mathrm{H}_{2} \mathrm{O}_{2}$ treatment were also selected according to the reaction model generated by BBD. The conditions were the same as that of the $\mathrm{O}_{3} / \mathrm{H}_{2} \mathrm{O}_{2}+\mathrm{BiPO}_{4} / \mathrm{UV}$ synergy technique to compare their mineralization efficiencies. However, $\mathrm{BiPO}_{4}$ was not added in the post-treatment process. Samples were directly transferred into the LP UV collimated beam system.

$\mathrm{O}_{3} / \mathrm{H}_{2} \mathrm{O}_{2}$ single-process. The initial experimental conditions and the procedures of the $\mathrm{O}_{3} / \mathrm{H}_{2} \mathrm{O}_{2}$ single-process were the same as those of the $\mathrm{O}_{3} / \mathrm{H}_{2} \mathrm{O}_{2}+\mathrm{BiPO}_{4} / \mathrm{UV}$ synergy technique; however, there was no post-treatment in this process. The $\mathrm{O}_{3} / \mathrm{H}_{2} \mathrm{O}_{2}$ treatment was sustained for 330 minutes.

$\mathrm{BiPO}_{4} / \mathrm{UV} / \mathrm{H}_{2} \mathrm{O}_{2}$ process. $\mathrm{BiPO}_{4} / \mathrm{UV} / \mathrm{H}_{2} \mathrm{O}_{2}$ process was carried out in the LP UV collimated beam system in the same manner as before. The initial amounts of $\mathrm{H}_{2} \mathrm{O}_{2}$ and $\mathrm{BiPO}_{4}$ loadings were equal to those used in the $\mathrm{O}_{3} / \mathrm{H}_{2} \mathrm{O}_{2}+\mathrm{BiPO}_{4} / \mathrm{UV}$ synergy technique. A specific amount of $\mathrm{BiPO}_{4}$ was added after agitation and ultrasonication for $10 \mathrm{~min}$ before irradiation. The experiment was continued for 330 minutes.

A water sample $(3 \mathrm{~mL})$ was taken every 30 minutes from the reactor in each experiment mentioned above to analyse the TOC concentration and $\mathrm{H}_{2} \mathrm{O}_{2}$ residues. Moreover, three replicates were made for each analytical measurement.

\subsection{Analytical methods}

The concentration of thiourea was analyzed by a HPLC system (Agilent 6120B, USA) equipped with a multi-wavelength UV detector (ESI, Text S1†). TOC was monitored with a Multi N/C 3100 TOC/TN analyzer. $\mathrm{H}_{2} \mathrm{O}_{2}$ was measured by a spectrophotometric method ${ }^{22}$ using a HACH DR6000 UV-vis spectrophotometer. Ammonium nitrogen was determined by salicylic acid spectrophotometry (HJ 536-2009 in China). Nitrate nitrogen, sulfate and chloridion were determined by ion chromatography (Metrohm 820 IC). The morphology and the structure of the $\mathrm{BiPO}_{4}$ photocatalyst were examined with a scanning electron microscope (SEM) and powder X-ray diffraction (XRD). The Brunauer Emmett Teller (BET) specific surface area and the pore size distribution of the $\mathrm{BiPO}_{4}$ photocatalyst were characterized by nitrogen adsorption at $77 \mathrm{~K}$ with Micromeritics 3020 . The degradation by-products of thiourea were analysed via high resolution mass spectrometry analysis carried out on Water IClass Acquity UPLC (Waters, UK) coupled with Vion IMS QToF (Waters, UK) (ESI, Text S2 $\dagger$ ).

\section{Results and discussion}

\subsection{Experimental design and condition selection}

The Box-Behnken statistical experiment design was employed to investigate the effects of three independent variables on the TOC and $\mathrm{H}_{2} \mathrm{O}_{2}$ residues as response functions. Table 2 depicts the three-factor three-level Box-Behnken experimental design and the observed and predicted values for the TOC and $\mathrm{H}_{2} \mathrm{O}_{2}$ residues by the developed quadratic model.

As mentioned before, RSM was used to estimate the parameters, indicating an empirical relationship between the input variables and the response, as shown in eqn (1) and (2). The quadratic model equation for predicting the response function (TOC, $\mathrm{H}_{2} \mathrm{O}_{2}$ residues) could be expressed by the following second-order polynomial equation in terms of the coded factors:

Table 2 Three-factor three-level BBD for RSM along with the observed and predicted responses

Independent

code variables

TOC

$\mathrm{H}_{2} \mathrm{O}_{2}$

\begin{tabular}{lrrrllcc} 
Run & $\mathrm{H}_{2} \mathrm{O}_{2}$ & $\mathrm{O}_{3}$ & $\mathrm{pH}$ & Observed & Predicted & Observed & Predicted \\
\hline 1 & 1 & 0 & -1 & 173.4 & 173.4 & 1046.9 & 1053 \\
2 & -1 & -1 & 0 & 179.2 & 177.4 & 2.22 & 0.86 \\
3 & -1 & 0 & -1 & 175 & 176.9 & 9.93 & 0.86 \\
4 & 0 & 0 & 0 & 175.6 & 168.2 & 442.27 & 416.51 \\
5 & 0 & -1 & 1 & 172.8 & 174.4 & 316.08 & 329.84 \\
6 & 1 & 1 & 0 & 160.2 & 161.8 & 855.02 & 862.77 \\
7 & 0 & 0 & 0 & 168.8 & 168.2 & 415.98 & 416.51 \\
8 & 0 & 1 & -1 & 175.6 & 174 & 350.26 & 336.5 \\
9 & 0 & -1 & -1 & 175 & 174.7 & 389.69 & 410.97 \\
10 & -1 & 0 & 1 & 182.4 & 182.2 & 0.86 & 0.86 \\
11 & 0 & 1 & 1 & 167.6 & 167.9 & 242.47 & 221.18 \\
12 & 0 & 0 & 0 & 166.2 & 168.2 & 405.46 & 416.51 \\
13 & 0 & 0 & 0 & 164.8 & 168.2 & 392.32 & 416.51 \\
14 & 1 & 0 & 1 & 163.4 & 161.6 & 844.51 & 858.04 \\
15 & 1 & -1 & 0 & 157 & 157.3 & 1120.6 & 1093.3 \\
16 & 0 & 0 & 0 & 165.4 & 168.2 & 426.5 & 416.51 \\
17 & -1 & 1 & 0 & 166 & 165.8 & 14.53 & 41.82
\end{tabular}




$$
\begin{aligned}
Y= & 168.16-6.07 X_{1}-1.82 X_{2}-1.60 X_{3}+4.10 X_{1} X_{2}-4.35 X_{1} X_{3} \\
& -1.45 X_{2} X_{3}-0.88 X_{1}{ }^{2}-1.68 X_{2}{ }^{2}+6.27 X_{3}^{2} \\
Z= & 416.51+479.94 X_{1}-45.78 X_{2}-49.11 X_{3}-69.46 X_{1} X_{2} \\
& -48.34 X_{1} X_{3}-8.54 X_{2} X_{3}+116.26 X_{1}{ }^{2} \\
& -34.68 X_{2}{ }^{2}-57.20 X_{3}{ }^{2}
\end{aligned}
$$

Here, $Y$ and $Z$ are the predicted responses for TOC and $\mathrm{H}_{2} \mathrm{O}_{2}$ residues, and $X_{1}, X_{2}$ and $X_{3}$ are the independent variables.

The statistical significance of the second-order polynomial model to predict the TOC and $\mathrm{H}_{2} \mathrm{O}_{2}$ residues was tested by the analysis of variance (ANOVA). The results of ANOVA are presented in Table S1 and Table S2 (ESI, Table S1 and S2 $\dagger$ ). The significance of each coefficient in eqn (1) and (2) was determined by the Fisher's $F$-test and the values of probability were greater than $F$.

A small probability value $(p<0.0001)$ indicated that the model was highly significant. The goodness of fit of the model was validated by the determination coefficient $\left(R^{2}\right)$. In this case, $R^{2}$ values were 0.99758 and 0.874188 , which showed high significance of the model. Also, the adequate precision greater than 4 (54.69 and 8.84 in this case) showed that the model could be used to navigate the design space defined by BBD. Adequate precision is a measure of the range in the predicted response relative to its associated error. The normality of data can be checked through the high correlation between observed and predicted data shown in Fig. S3 (ESI, Fig. S3†), which indicates their low discrepancies.

To study the interaction effects between the variables (initial concentration of polymer, initial concentration of $\mathrm{H}_{2} \mathrm{O}_{2}, \mathrm{pH}$ and recirculation rate), the $3 \mathrm{D}$ response surface and $2 \mathrm{D}$ contour curves based on the quadratic model were plotted, as shown in Fig. 2(a-f).

As illustrated in Fig. 2(a-f), TOC was significantly affected by the initial $\mathrm{H}_{2} \mathrm{O}_{2}$ dosage and $\mathrm{O}_{3}$ concentration. It can be seen that TOC decreased with increasing $\mathrm{H}_{2} \mathrm{O}_{2}$ dosage and $\mathrm{O}_{3}$ concentration. The effects of the initial $\mathrm{H}_{2} \mathrm{O}_{2}$ dosage and the $\mathrm{O}_{3}$ concentration are mainly due to the generation of $\cdot \mathrm{OH}$ by $\mathrm{H}_{2} \mathrm{O}_{2}$ and $\mathrm{O}_{3}$. The more the $\cdot \mathrm{OH}$, the higher the mineralization efficiency. Also, it can be seen that minimum TOC is achieved at $\mathrm{pH}$ of 7. In alkaline solutions, the dissociated form of hydrogen peroxide $\left(\mathrm{HO}_{2}{ }^{-}\right)$reacts with $\cdot \mathrm{OH}$ more than 2 orders of magnitude faster than hydrogen peroxide. ${ }^{23}$ Therefore, the oxidation efficiency decreases as $\cdot \mathrm{OH}$ species are consumed. However, in acidic solutions, thiourea is stable and relatively hard to be mineralized. As for the amount of $\mathrm{H}_{2} \mathrm{O}_{2}$ residues, data are illustrated from Fig. 2(d)-(f). The initial $\mathrm{H}_{2} \mathrm{O}_{2}$ dosage is the main factor that influences the amount of $\mathrm{H}_{2} \mathrm{O}_{2}$ residues; however, the influence of $\mathrm{pH}$ and $\mathrm{O}_{3}$ concentration is much less pronounced than that of the initial $\mathrm{H}_{2} \mathrm{O}_{2}$ dosage. This is also confirmed in Table S2, $\dagger$ which shows the significance of the factors and their interaction.

To investigate the mineralization and degradation efficiency of the $\mathrm{O}_{3} / \mathrm{H}_{2} \mathrm{O}_{2}+\mathrm{BiPO} 4 / \mathrm{UV}$ synergy technique, we chose the initial experimental conditions of $\mathrm{O}_{3} / \mathrm{H}_{2} \mathrm{O}_{2}$ treatment based on the quadratic model equation calculated by BBD. According to these equations, specific experimental conditions were selected to achieve the maximum mineralization efficiency of thiourea under a targeted amount of $\mathrm{H}_{2} \mathrm{O}_{2}$ residues. In this experiment, we set the experimental conditions to obtain $70 \mathrm{mg} \mathrm{L}^{-1} \mathrm{H}_{2} \mathrm{O}_{2}$ residues from the $\mathrm{O}_{3} / \mathrm{H}_{2} \mathrm{O}_{2}$ treatment with the maximum mineralization efficiency. According to this target, the ozone concentration was set at $55.71 \mathrm{mg} \mathrm{L}^{-1}$, the initial concentration of $\mathrm{H}_{2} \mathrm{O}_{2}$ was $435 \mathrm{mg} \mathrm{L}^{-1}$, and the initial $\mathrm{pH}$ value was 9.20 .

\subsection{Comparison of mineralization efficiencies among different treatment processes}

In this study, degradation efficiencies were compared among different treatment processes. As observed in Fig. 3, 89.14\% of thiourea was degraded by $\mathrm{O}_{3} / \mathrm{H}_{2} \mathrm{O}_{2}$ within only 30 minutes. The chemical construction of thiourea includes a double bond between carbon and sulfur. It can be easily oxidized by an oxidizing agent, especially by strong oxidants such as ozone $\left(E^{0}\right.$ $=2.07 \mathrm{eV})$, hydrogen peroxide $\left(E^{0}=1.28 \mathrm{eV}\right)$ and hydroxyl radicals $\left(E^{0}=2.8 \mathrm{eV}\right)$. The $\cdot \mathrm{OH}$ species generated by $\mathrm{O}_{3} / \mathrm{H}_{2} \mathrm{O}_{2}$ as well as $\mathrm{O}_{3}$ and $\mathrm{H}_{2} \mathrm{O}_{2}$ oxidize thiourea into other products, which may contribute to the degradation of thiourea. The degradation efficiency of thiourea by $\mathrm{UV} / \mathrm{H}_{2} \mathrm{O}_{2}$ and $\mathrm{BiPO} 4 / \mathrm{UV} / \mathrm{H}_{2} \mathrm{O}_{2}$ processes was also investigated and compared with that of $\mathrm{O}_{3} /$ $\mathrm{H}_{2} \mathrm{O}_{2}$. In only 30 minutes of reaction time, $69.35 \%$ and $71.90 \%$ of thiourea were degraded by $\mathrm{UV} / \mathrm{H}_{2} \mathrm{O}_{2}$ and $\mathrm{BiPO} / \mathrm{UV} / \mathrm{H}_{2} \mathrm{O}_{2}$, respectively, which were much lower than the value obtained for $\mathrm{O}_{3} / \mathrm{H}_{2} \mathrm{O}_{2}$. The lower degradation efficiency might be due to the absence of $\mathrm{O}_{3}$ in the process, which reduced their oxidizability.

The $\mathrm{O}_{3} / \mathrm{H}_{2} \mathrm{O}_{2}$ process only reduced $23.125 \mathrm{mg} \mathrm{L}^{-1}$ TOC, whereas $\mathrm{O}_{3} / \mathrm{H}_{2} \mathrm{O}_{2}+\mathrm{UV}$ achieved TOC reduction of $22.5 \mathrm{mg} \mathrm{L}^{-1}$; also, the performance of the $\mathrm{BiPO}_{4} / \mathrm{UV} / \mathrm{H}_{2} \mathrm{O}_{2}$ single-process was much lower than that of the $\mathrm{O}_{3} / \mathrm{H}_{2} \mathrm{O}_{2}+\mathrm{BiPO}_{4} / \mathrm{UV}$ synergy technique. Nevertheless, Fig. 3 shows that the $\mathrm{O}_{3} / \mathrm{H}_{2} \mathrm{O}_{2}$ singleprocess achieved more TOC removal in the first half of the treatment process than the $\mathrm{BiPO}_{4} / \mathrm{UV} / \mathrm{H}_{2} \mathrm{O}_{2}$ single-process; however, in the second half, the TOC removal rate of the $\mathrm{O}_{3} /$ $\mathrm{H}_{2} \mathrm{O}_{2}$ single-process was exceeded by that of the $\mathrm{BiPO}_{4} / \mathrm{UV} / \mathrm{H}_{2} \mathrm{O}_{2}$ single-process. Based on this phenomenon, the $\mathrm{O}_{3} / \mathrm{H}_{2} \mathrm{O}_{2}+$ $\mathrm{BiPO}_{4} / \mathrm{UV}$ synergy technique was applied to exert higher TOC removal and generate synergy effect. The amount of TOC removal by the $\mathrm{O}_{3} / \mathrm{H}_{2} \mathrm{O}_{2}+\mathrm{BiPO}_{4} / \mathrm{UV}$ synergy technique was 1.8 and 1.5 times higher than that of the $\mathrm{O}_{3} / \mathrm{H}_{2} \mathrm{O}_{2}$ single-process and the $\mathrm{BiPO}_{4} / \mathrm{UV} / \mathrm{H}_{2} \mathrm{O}_{2}$ single-process, respectively. Also, the TOC removal was much higher than that without $\mathrm{BiPO}_{4}$ addition, which was 1.9 times that of the $\mathrm{O}_{3} / \mathrm{H}_{2} \mathrm{O}_{2}+\mathrm{UV}$ process. This is mainly due to two factors. The first factor is the synergy between $\mathrm{BiPO}_{4}$ and $\mathrm{H}_{2} \mathrm{O}_{2}$ residues from $\mathrm{O}_{3} / \mathrm{H}_{2} \mathrm{O}_{2}$. The $\mathrm{H}_{2} \mathrm{O}_{2}$ residues from $\mathrm{O}_{3} / \mathrm{H}_{2} \mathrm{O}_{2}$ are not wasted, and they further generate $\cdot \mathrm{OH}$ through UV irradiation; $\mathrm{H}_{2} \mathrm{O}_{2}$ residues can also capture $\mathrm{e}^{-}$generated in $\mathrm{BiPO}_{4}$, which can increase the separation efficiency of $\mathrm{e}^{-}$and $\mathrm{h}^{+}{ }^{20}$ Also, a part of $\mathrm{H}_{2} \mathrm{O}_{2}$ is utilized in $\mathrm{O}_{3} / \mathrm{H}_{2} \mathrm{O}_{2}$; thus, we can avoid the negative effect on the synergy between $\mathrm{BiPO}_{4}$ and $\mathrm{H}_{2} \mathrm{O}_{2}$ due to excess $\mathrm{H}_{2} \mathrm{O}_{2}$. In $\mathrm{BiPO}_{4} / \mathrm{UV} / \mathrm{H}_{2} \mathrm{O}_{2}$ single-process, excess $\mathrm{H}_{2} \mathrm{O}_{2}$ shows inhibition of the synergy between $\mathrm{BiPO}_{4}$ and $\mathrm{H}_{2} \mathrm{O}_{2}$; it can occupy the holes in $\mathrm{BiPO}_{4}$ but cannot improve the separation efficiency of $\mathrm{e}^{-}$and $\mathrm{h}^{+}$. Thus, the TOC removal of the $\mathrm{BiPO}_{4} / \mathrm{UV} / \mathrm{H}_{2} \mathrm{O}_{2}$ single-process is limited. 
(a)

(c)
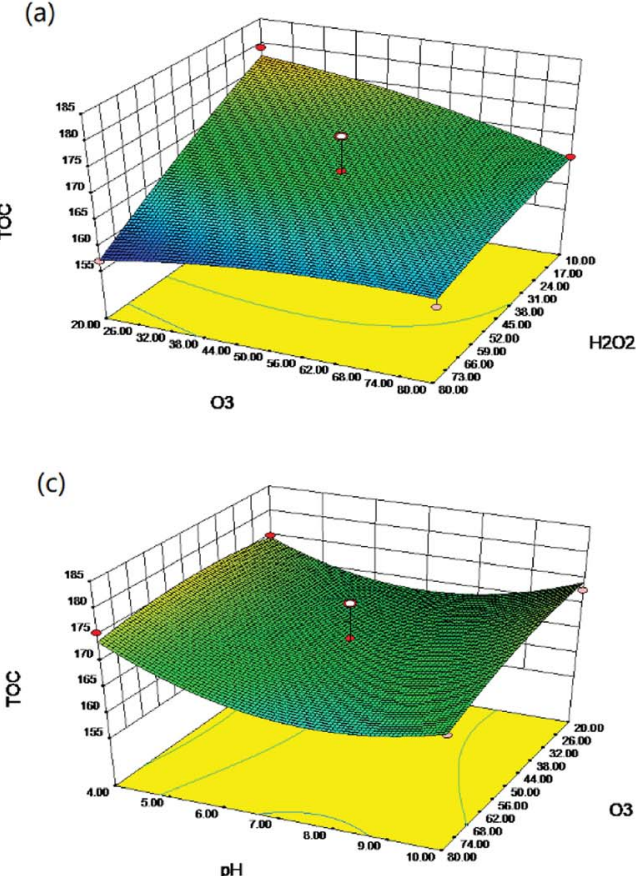

(e)

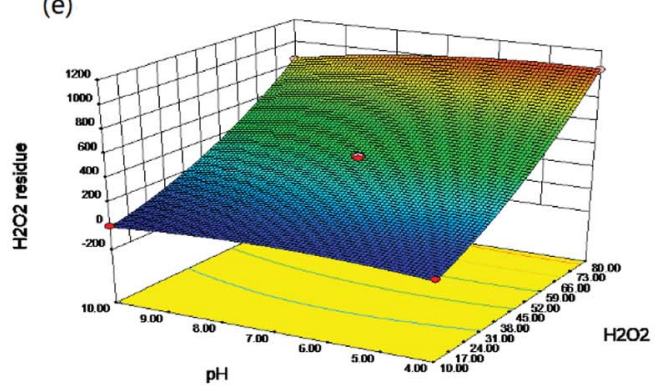

(b)

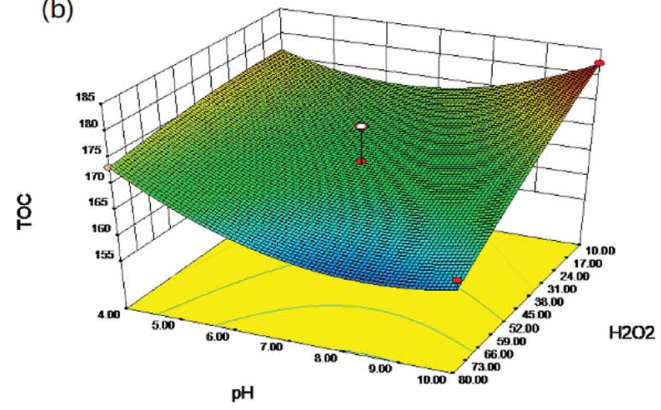

(d)

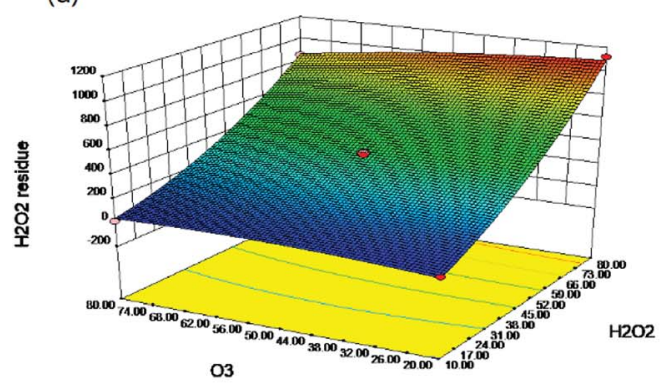

(f)

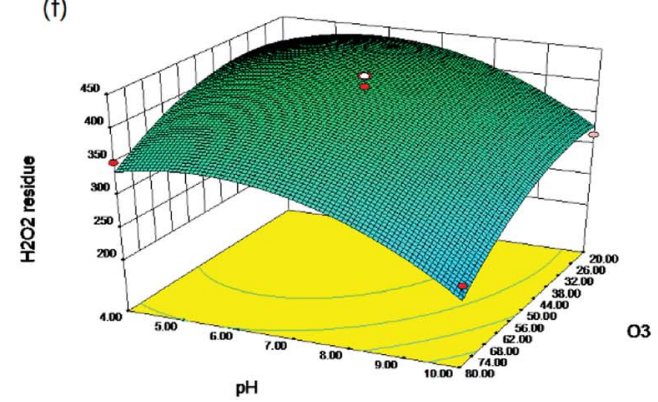

Fig. 2 Interaction effects of different parameters on TOC (a-c) and $\mathrm{H}_{2} \mathrm{O}_{2}$ residues (d-f) using 3D response surface and 2D contours: (a) $\mathrm{O}_{3}$ concentration and initial $\mathrm{H}_{2} \mathrm{O}_{2}$ dosage, (b) $\mathrm{pH}$ and $\mathrm{H}_{2} \mathrm{O}_{2}$ dosage, (c) $\mathrm{pH}$ and $\mathrm{O}_{3}$ concentration, (d) $\mathrm{O}_{3}$ concentration and $\mathrm{H}_{2} \mathrm{O}_{2}$ dosage, (e) $\mathrm{pH}$ and $\mathrm{H}_{2} \mathrm{O}_{2}$ dosage, (f) $\mathrm{pH}$ and $\mathrm{O}_{3}$ concentration.

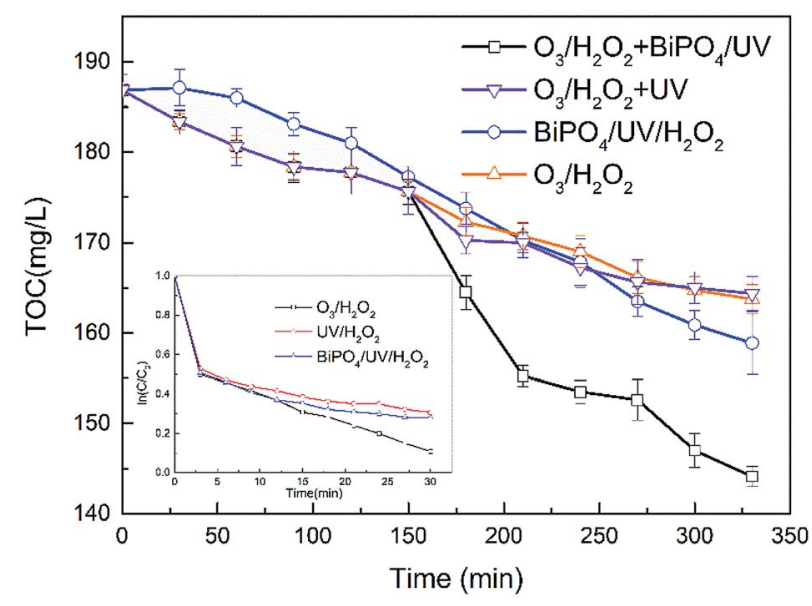

Fig. 3 Comparison of mineralization efficiencies among $\mathrm{O}_{3} / \mathrm{H}_{2} \mathrm{O}_{2}+$ $\mathrm{BiPO} 4 / \mathrm{UV}$ synergy technique, $\mathrm{O}_{3} / \mathrm{H}_{2} \mathrm{O}_{2}+\mathrm{UV}, \mathrm{O}_{3} / \mathrm{H}_{2} \mathrm{O}_{2}$ and $\mathrm{BiPO} 4 /$ $U V / \mathrm{H}_{2} \mathrm{O}_{2}$ processes and the degradation efficiencies among $\mathrm{O}_{3} / \mathrm{H}_{2} \mathrm{O}_{2}$, $\mathrm{UV} / \mathrm{H}_{2} \mathrm{O}_{2}$ and $\mathrm{BiPO}_{4} / \mathrm{UV} / \mathrm{H}_{2} \mathrm{O}_{2}$.
The second factor is the electron transfer oxidation of holes. - $\mathrm{OH}$ tends to abstract hydrogen from $\mathrm{C}-\mathrm{H}$ bonds or add hydrogen to unsaturated carbon-sulfur bonds; thus, it is superior in thiourea degradation but inferior in further mineralization. As for $\mathrm{O}_{3} / \mathrm{H}_{2} \mathrm{O}_{2}$, it can only generate $\cdot \mathrm{OH}$ that is inferior in mineralization; thus, the amount of TOC removal is much lower than that of the processes containing $\mathrm{BiPO}_{4}$. In contrast, $\mathrm{BiPO}_{4}$ in $\mathrm{BiPO}_{4} / \mathrm{UV}$ can generate holes that can directly mineralize the by-products of $\mathrm{O}_{3} / \mathrm{H}_{2} \mathrm{O}_{2}$.

\subsection{Comparison of $\mathrm{H}_{2} \mathrm{O}_{2}$ utilization among different treatment processes}

The $\mathrm{O}_{3} / \mathrm{H}_{2} \mathrm{O}_{2}+\mathrm{BiPO}_{4} / \mathrm{UV}$ synergy technique could greatly improve the utilization efficiency of hydrogen peroxide, especially in the $\mathrm{BiPO}_{4} / \mathrm{UV}$ process, as shown in Fig. 4. After the treatment of $\mathrm{O}_{3} / \mathrm{H}_{2} \mathrm{O}_{2}$, about $70 \mathrm{mg} \mathrm{\textrm {L } ^ { - 1 }}$ hydrogen peroxide was retained, which could be utilized by $\mathrm{BiPO}_{4}$ photocatalysis in less than $1 \mathrm{~h}$. The $\mathrm{O}_{3} / \mathrm{H}_{2} \mathrm{O}_{2}$ single-process and $\mathrm{O}_{3} / \mathrm{H}_{2} \mathrm{O}_{2}+\mathrm{UV}$ needed 
more than 2 and 3 hours to consume hydrogen peroxide residues. Even though the consumption rate of hydrogen peroxide was higher in the $\mathrm{BiPO}_{4} / \mathrm{UV} / \mathrm{H}_{2} \mathrm{O}_{2}$ single-process, the TOC removal rate of thiourea was $15 \%$, as mentioned before, which was much lower than that of the $\mathrm{O}_{3} / \mathrm{H}_{2} \mathrm{O}_{2}+\mathrm{BiPO}_{4} / \mathrm{UV}$ synergy technique. It has been proven that hydroxide radicals are quenched by additional hydrogen peroxide species; $;^{\mathbf{2 4 , 2 5}}$ thus, the hydroxide radicals generated in $\mathrm{BiPO}_{4} / \mathrm{UV} / \mathrm{H}_{2} \mathrm{O}_{2}$ single-process were not attached to thiourea but were consumed by extra $\mathrm{H}_{2} \mathrm{O}_{2}$ according to equation: ${ }^{26}$

$$
\mathrm{H}_{2} \mathrm{O}_{2}+\cdot \mathrm{OH} \rightarrow \mathrm{H}_{2} \mathrm{O}+\mathrm{HO}_{2}
$$

Therefore, excess $\mathrm{H}_{2} \mathrm{O}_{2}$ could lead to the consumption of active oxidizing hydroxyl radicals by a reaction other than the thiourea mineralization reaction, consequently reducing the rate of the latter reaction and wasting considerable $\mathrm{H}_{2} \mathrm{O}_{2}$ reagent.

In the $\mathrm{O}_{3} / \mathrm{H}_{2} \mathrm{O}_{2}+\mathrm{BiPO}_{4} / \mathrm{UV}$ synergy technique, it is believed that $\mathrm{H}_{2} \mathrm{O}_{2}$ generates more $\cdot \mathrm{OH}$ in $\mathrm{BiPO}_{4} / \mathrm{UV}$ because of the synergy between $\mathrm{BiPO}_{4}$ and $\mathrm{H}_{2} \mathrm{O}_{2}$. Electron spin resonance (ESR) was carried out to investigate the hydroxyl radicals generated by $\mathrm{H}_{2} \mathrm{O}_{2}, \mathrm{BiPO}_{4}$ or both $\mathrm{BiPO}_{4}$ and $\mathrm{H}_{2} \mathrm{O}_{2}$ under UV irradiation. We measured hydroxyl radicals by ESR using DMPO as the spin-trap reagent. As shown in Fig. 5, the characteristic four peaks of DMPO--OH with the intensities of $1: 2: 2: 1$ appeared in all spectra. The intensity of $\cdot \mathrm{OH}$ generated in $\mathrm{BiPO}_{4}$ after the addition of $70 \mathrm{mg} \mathrm{\textrm {L } ^ { - 1 }}$ hydrogen peroxide was much higher than that in the $\mathrm{H}_{2} \mathrm{O}_{2}$ system and $\mathrm{BiPO}_{4}$ system. The result was in accordance with that of Elmolla's research. ${ }^{27}$ As an electron scavenger, $\mathrm{H}_{2} \mathrm{O}_{2}$ can react with $\mathrm{e}^{-}$, as shown in the following equation:

$$
\mathrm{H}_{2} \mathrm{O}_{2}+2 \mathrm{e}^{-} \rightarrow \cdot \mathrm{OH}+\mathrm{OH}^{-}
$$

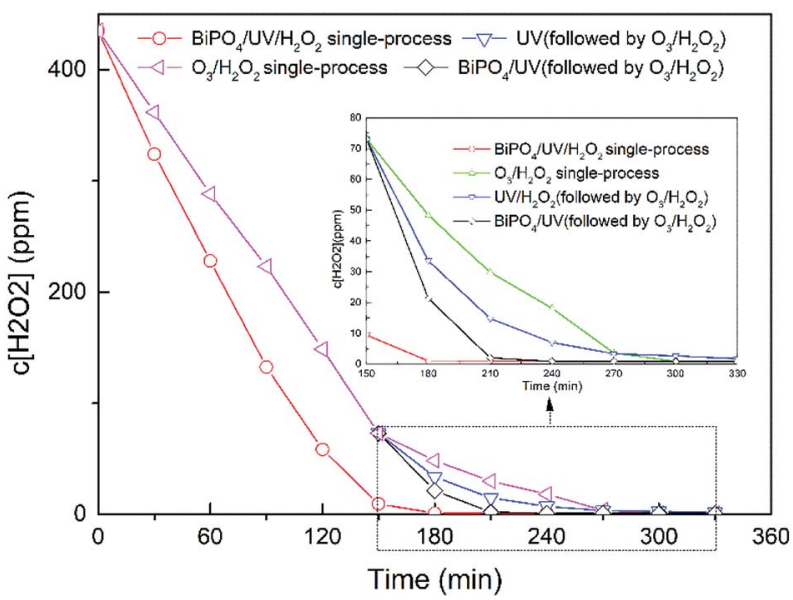

Fig. 4 Comparison of $\mathrm{H}_{2} \mathrm{O}_{2}$ utilization in different processes. The concentration of thiourea was $1.2 \mathrm{~g} \mathrm{~L}^{-1}$, the concentration of ammonia nitrogen was $140 \mathrm{mg} \mathrm{L}^{-1}$, the initial concentration of $\mathrm{H}_{2} \mathrm{O}_{2}$ was $435 \mathrm{mg} \mathrm{L}^{-1}, \mathrm{O}_{3}$ concentration was $55.71 \mathrm{mg} \mathrm{L}^{-1}, \mathrm{UV}$ intensity was 4.73 $\mathrm{mW} \mathrm{cm}{ }^{-2}$, and the $\mathrm{BiPO}_{4}$ loading was $0.5 \mathrm{~g} \mathrm{~L}^{-1}$.

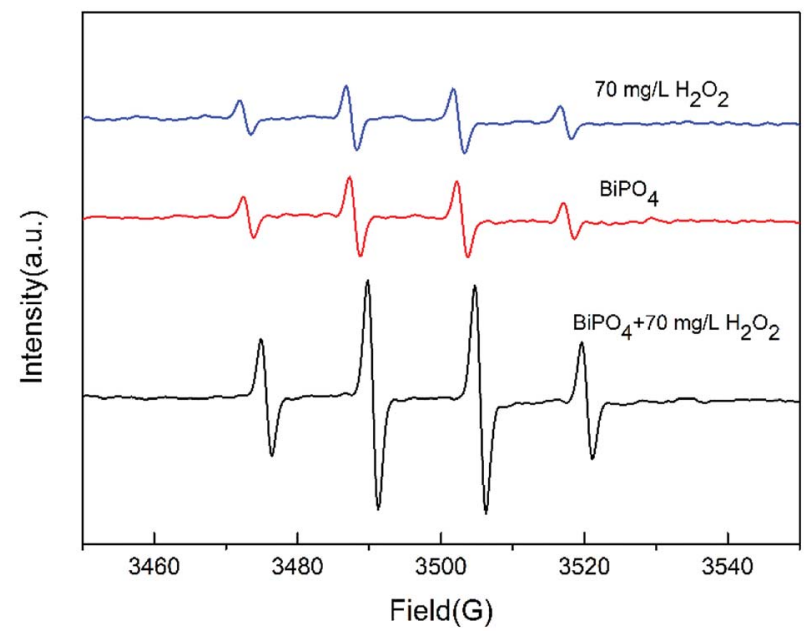

Fig. 5 DMPO spin-trapping ESR spectra under UV irradiation for 2 min at room temperature water in the presence of $\mathrm{BiPO}_{4}, \mathrm{H}_{2} \mathrm{O}_{2}$ or both $\mathrm{BiPO}_{4}$ and $\mathrm{H}_{2} \mathrm{O}_{2}$.

As explained before, an appropriate amount of $\mathrm{H}_{2} \mathrm{O}_{2}$ will capture the electrons in $\mathrm{BiPO}_{4}$, increasing the separation efficiency of $\mathrm{e}^{-}$and $\mathrm{h}^{+}$. This reaction also motivates $\mathrm{H}_{2} \mathrm{O}_{2}$ to generate $\cdot \mathrm{OH}$. As a result, the electron capture process combined with the UV irradiation process increases $\cdot \mathrm{OH}$ generation; thus, it accelerates the consumption rate of residual $\mathrm{H}_{2} \mathrm{O}_{2}$ from $\mathrm{O}_{3} / \mathrm{H}_{2} \mathrm{O}_{2}$ treatment. Also, more $\cdot \mathrm{OH}$ generation indicates less residual $\mathrm{H}_{2} \mathrm{O}_{2}$, and it will change the ratio of $\cdot \mathrm{OH}$ and $\mathrm{H}_{2} \mathrm{O}_{2}$; thus, $\cdot \mathrm{OH}$ scavenge reaction will be limited and $\mathrm{H}_{2} \mathrm{O}_{2}$ will be used efficiently. Nonetheless, the residual $\mathrm{H}_{2} \mathrm{O}_{2}$ from $\mathrm{O}_{3}$ / $\mathrm{H}_{2} \mathrm{O}_{2}$ not only increases the separation of $\mathrm{e}^{-}$and $\mathrm{h}^{+}$in $\mathrm{BiPO}_{4}$, but also results in $\cdot \mathrm{OH}$ generation. Thus, high degradation of thiourea by $\mathrm{O}_{3} / \mathrm{H}_{2} \mathrm{O}_{2}$ and residual $\mathrm{H}_{2} \mathrm{O}_{2}$ is efficiently utilized by the synergy between $\mathrm{H}_{2} \mathrm{O}_{2}$ and $\mathrm{BiPO}_{4}$, attaining faster $\mathrm{H}_{2} \mathrm{O}_{2}$ consumption and higher TOC removal.

\subsection{Effect of hydrogen peroxide}

To investigate the effect of $\mathrm{H}_{2} \mathrm{O}_{2}$, different concentrations of $\mathrm{H}_{2} \mathrm{O}_{2}$ were employed in the $\mathrm{O}_{3} / \mathrm{H}_{2} \mathrm{O}_{2}+\mathrm{BiPO}_{4} / \mathrm{UV}$ synergy technique. Based on the $\mathrm{BBD}$ model introduced before, we could predict the amount of residual $\mathrm{H}_{2} \mathrm{O}_{2}$ of $\mathrm{O}_{3} / \mathrm{H}_{2} \mathrm{O}_{2}$ under different $\mathrm{H}_{2} \mathrm{O}_{2}$ concentrations. We set $70 \mathrm{mg} \mathrm{L}^{-1}, 140 \mathrm{mg} \mathrm{L}^{-1}$ and $280 \mathrm{mg} \mathrm{L}^{-1}$ as target $\mathrm{H}_{2} \mathrm{O}_{2}$ residues; $17.34 \mathrm{~mL}, 22.09 \mathrm{~mL}$ and $47.63 \mathrm{~mL} \mathrm{H}_{2} \mathrm{O}_{2}$ were selected as initial concentrations.

Table 3 shows various experimental parameters. Under these treatment conditions, we compared the TOC removal rates between $\mathrm{BiPO}_{4} / \mathrm{UV}$ and $\mathrm{UV}$ after the treatment of $\mathrm{O}_{3} / \mathrm{H}_{2} \mathrm{O}_{2}$. Fig. 6(a) shows that $\mathrm{BiPO}_{4}$ can significantly improve TOC removal under about $70 \mathrm{mg} \mathrm{L^{-1 }}$ residual $\mathrm{H}_{2} \mathrm{O}_{2}$. The TOC removal was 2.8 times that of the treatment without $\mathrm{BiPO}_{4}$ addition. However, along with the increase in residual $\mathrm{H}_{2} \mathrm{O}_{2}$, the mineralization ability of $\mathrm{BiPO}_{4} / \mathrm{UV}$ was inhibited. We can see from Fig. 6(b) and (c) that the mineralization efficiency of $\mathrm{BiPO}_{4} / \mathrm{UV}$ was lower than that of the treatment without the $\mathrm{BiPO}_{4}$ addition in the initial 60 and 90 minutes. This phenomenon can be explained by the following equation: ${ }^{28}$ 
Table 3 Different experimental parameters for the $\mathrm{O}_{3} / \mathrm{H}_{2} \mathrm{O}_{2}$ treatment

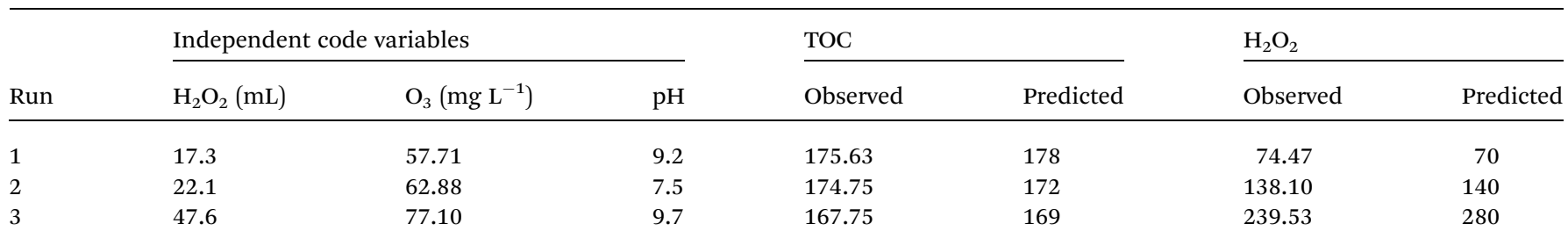

$$
\mathrm{H}_{2} \mathrm{O}_{2}+2 \mathrm{~h}^{+} \rightarrow \mathrm{O}_{2}+2 \mathrm{H}^{+}
$$

Excess $\mathrm{H}_{2} \mathrm{O}_{2}$ might be absorbed on the surface of the $\mathrm{BiPO}_{4}$ photocatalyst and can react with the holes on the surface of the catalyst. Since holes govern the mineralization efficiency of thiourea, consumption of holes by the absorbed $\mathrm{H}_{2} \mathrm{O}_{2}$ can result in retarded photocatalytic mineralization efficiency of thiourea. Also, excessive $\mathrm{H}_{2} \mathrm{O}_{2}$ can counteract the synergy between $\mathrm{H}_{2} \mathrm{O}_{2}$ residues and $\mathrm{BiPO}_{4}$ photocatalyst. Excessive $\mathrm{H}_{2} \mathrm{O}_{2}$ may scavenge the holes as well as $\cdot \mathrm{OH}$ generated by $\mathrm{e}^{-}$and $\mathrm{H}_{2} \mathrm{O}_{2}$. Thus, adequate $\mathrm{H}_{2} \mathrm{O}_{2}$ can improve the synergy between residual $\mathrm{H}_{2} \mathrm{O}_{2}$ and $\mathrm{BiPO}_{4}$, but superfluous $\mathrm{H}_{2} \mathrm{O}_{2}$ may cause negative effects and lead to the decline in the mineralization efficiency of the $\mathrm{O}_{3} /$ $\mathrm{H}_{2} \mathrm{O}_{2}+\mathrm{BiPO}_{4} / \mathrm{UV}$ synergy technique.

As shown in Fig. 7, we also investigated the residual $\mathrm{H}_{2} \mathrm{O}_{2}$ consumption rate by $\mathrm{BiPO}_{4} / \mathrm{UV}$ under conditions described in Table 3. The consumption rate of residual $\mathrm{H}_{2} \mathrm{O}_{2}$ by UV was calculated under $70 \mathrm{mg} \mathrm{L}^{-1}$, $140 \mathrm{mg} \mathrm{L}^{-1}$ and $280 \mathrm{mg} \mathrm{L}^{-1} \mathrm{H}_{2} \mathrm{O}_{2}$ concentrations, which conformed to pseudo first order reaction kinetics (eqn (6)):

$$
-\ln \left(\frac{c\left[\mathrm{H}_{2} \mathrm{O}_{2}\right]_{t}}{c\left[\mathrm{H}_{2} \mathrm{O}_{2}\right]_{0}}\right)_{\text {average }}=k_{0} t+c
$$

Here, $k_{0}$ is the reaction kinetic constant, $c$ is the intercept, $c$ $\left[\mathrm{H}_{2} \mathrm{O}_{2}\right]_{t}$ is the $\mathrm{H}_{2} \mathrm{O}_{2}$ concentration after reaction for different periods, and $c\left[\mathrm{H}_{2} \mathrm{O}_{2}\right]_{0}$ is the initial $\mathrm{H}_{2} \mathrm{O}_{2}$ concentration. The residual $\mathrm{H}_{2} \mathrm{O}_{2}$ consumption rates by the $\mathrm{BiPO}_{4} / \mathrm{UV}$ system with different $\mathrm{H}_{2} \mathrm{O}_{2}$ concentrations were fit to eqn (7):

$$
-\ln \left(\frac{c\left[\mathrm{H}_{2} \mathrm{O}_{2}\right]_{t}}{c\left[\mathrm{H}_{2} \mathrm{O}_{2}\right]_{0}}\right)=k_{\mathrm{p}} t^{2}+k_{\mathrm{j}} t+c
$$

Here, $k_{\mathrm{p}}$ and $k_{\mathrm{j}}$ are the coefficients of the $\mathrm{BiPO}_{4} / \mathrm{UV}$ system with different $\mathrm{H}_{2} \mathrm{O}_{2}$ residues, $c$ is the intercept, $c\left[\mathrm{H}_{2} \mathrm{O}_{2}\right]_{t}$ is the $\mathrm{H}_{2} \mathrm{O}_{2}$ concentration after reaction for different periods, and $c$ $\left[\mathrm{H}_{2} \mathrm{O}_{2}\right]_{0}$ is the initial $\mathrm{H}_{2} \mathrm{O}_{2}$ concentration.

As shown in Fig. 7, $\mathrm{BiPO}_{4}$ can accelerate $\mathrm{H}_{2} \mathrm{O}_{2}$ consumption under $70 \mathrm{mg} \mathrm{L}^{-1}$ of residual $\mathrm{H}_{2} \mathrm{O}_{2}$. Nevertheless, along with the increase in residual $\mathrm{H}_{2} \mathrm{O}_{2}$ to $140 \mathrm{mg} \mathrm{L}^{-1}$ and $280 \mathrm{mg} \mathrm{L}^{-1}, \mathrm{BiPO}_{4}$ inhibited $\mathrm{H}_{2} \mathrm{O}_{2}$ consumption at the beginning; however, after

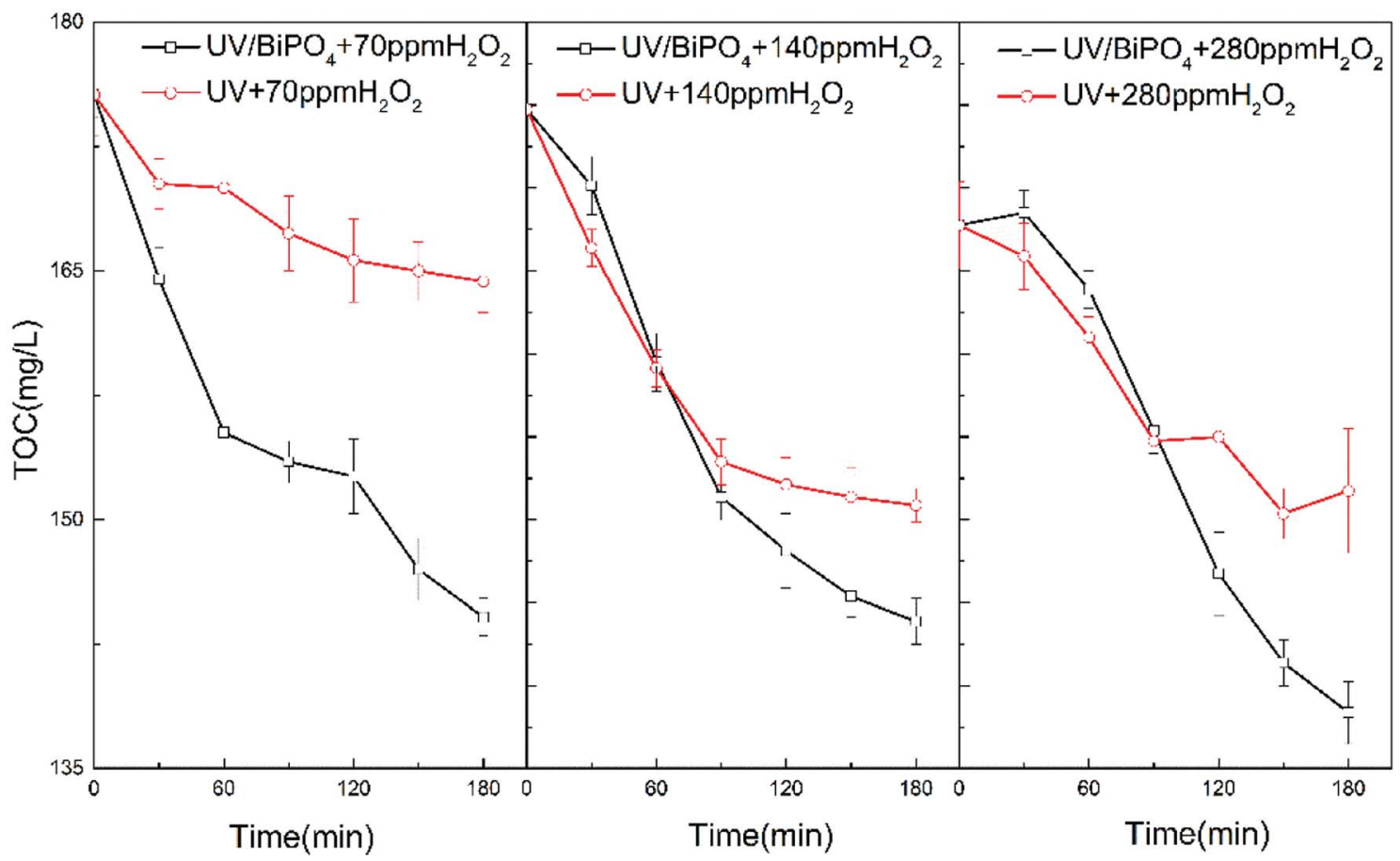

Fig. 6 Effect of different $\mathrm{H}_{2} \mathrm{O}_{2}$ residues of the $\mathrm{H}_{2} \mathrm{O}_{2} / \mathrm{O}_{3}$ pre-treatment on the TOC removal: parameters carried out according to Run 2 with $74.47 \mathrm{mg} \mathrm{L}^{-1} \mathrm{H}_{2} \mathrm{O}_{2}$ residues, Run 3 with $138.10 \mathrm{mg} \mathrm{L}^{-1} \mathrm{H}_{2} \mathrm{O}_{2}$ residues and Run 3 with $239.53 \mathrm{mg} \mathrm{L}^{-1} \mathrm{H}_{2} \mathrm{O}_{2}$ residues. 


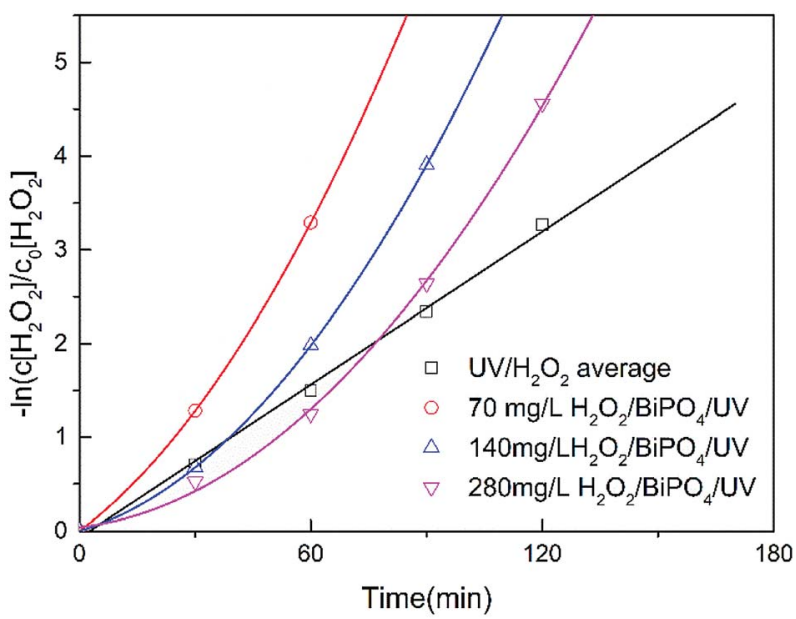

Fig. 7 The consumption rate of $\mathrm{H}_{2} \mathrm{O}_{2}$ under $\mathrm{UV}$ and $\mathrm{BiPO}_{4} / \mathrm{UV}$ with about 70, 140, $280 \mathrm{mg} \mathrm{L}^{-1} \mathrm{H}_{2} \mathrm{O}_{2}$ residues.

the residual $\mathrm{H}_{2} \mathrm{O}_{2}$ was partially consumed, the consumption rate was expedited and exceeded the rate of the UV system. This phenomenon shows inactivation of $\mathrm{H}_{2} \mathrm{O}_{2}$ in the $\mathrm{BiPO}_{4} / \mathrm{UV}$ system under high concentrations of $\mathrm{H}_{2} \mathrm{O}_{2}$ residues because UV irradiation is first absorbed by the $\mathrm{BiPO}_{4}$ photocatalyst. Under this circumstance, less $\mathrm{H}_{2} \mathrm{O}_{2}$ can be driven to generate $\cdot \mathrm{OH}$, and the consumption amount of $\mathrm{H}_{2} \mathrm{O}_{2}$ decreases. Although, $\mathrm{e}^{-}$and $\mathrm{h}^{+}$on the surface of $\mathrm{BiPO}_{4}$ can consume $\mathrm{H}_{2} \mathrm{O}_{2}$ as explained before, considering that the amount of the $\mathrm{BiPO}_{4}$ photocatalyst is constant under these three conditions, the consumption amount of $\mathrm{H}_{2} \mathrm{O}_{2}$ does not change. Thus, the consumption rate of $\mathrm{H}_{2} \mathrm{O}_{2}$ in $\mathrm{BiPO}_{4} / \mathrm{UV}$ post-treatment decreases along with the increase in $\mathrm{H}_{2} \mathrm{O}_{2}$ concentration. This influences the TOC removal rate of the $\mathrm{O}_{3} / \mathrm{H}_{2} \mathrm{O}_{2}+\mathrm{BiPO}_{4} / \mathrm{UV}$ synergy technique and also the utilization efficiency of the $\mathrm{H}_{2} \mathrm{O}_{2}$ reagent.

\subsection{Effect of photocatalyst loading}

The amount of $\mathrm{BiPO}_{4}$ is another important parameter in the $\mathrm{O}_{3} /$ $\mathrm{H}_{2} \mathrm{O}_{2}+\mathrm{BiPO}_{4} / \mathrm{UV}$ synergy technique. To investigate the effect of $\mathrm{BiPO}_{4}$ loading on the TOC removal of thiourea by the $\mathrm{O}_{3} / \mathrm{H}_{2} \mathrm{O}_{2}+$ $\mathrm{BiPO}_{4} / \mathrm{UV}$ synergy technique, $0.2 \mathrm{~g} \mathrm{~L}^{-1}, 0.5 \mathrm{~g} \mathrm{~L}^{-1}, 1.0 \mathrm{~g} \mathrm{~L}^{-1}$ and $1.5 \mathrm{~g} \mathrm{~L}^{-1}$ of $\mathrm{BiPO}_{4}$ were loaded in the post-treatment process. We used TOC removal to show the treatment effect and used the ratio between the TOC removal and the $\mathrm{BiPO}_{4}$ loading to show the catalyst efficiency. As shown in Fig. 8, when the amount of $\mathrm{BiPO}_{4}$ was increased from $0.2 \mathrm{~g} \mathrm{~L}^{-1}$ to $0.5 \mathrm{~g} \mathrm{~L}^{-1}$, the TOC removal improved from $6.125 \mathrm{mg} \mathrm{L}^{-1}$ to $30.875 \mathrm{mg} \mathrm{L}^{-1}$ and the catalyst efficiency was greatly enhanced. However, upon further increasing the $\mathrm{BiPO}_{4}$ loading to $1.0 \mathrm{~g} \mathrm{~L}^{-1}$ and $1.5 \mathrm{~g} \mathrm{~L}^{-1}$, neither the TOC removal nor the catalyst efficiency decreased significantly, revealing negative effect on thiourea mineralization. This phenomenon showed a similar tendency to that reported in other researches: ${ }^{29,30}$ the mineralization efficiency cannot always increase with the increase in catalyst loading. Many studies have shown that the mineralization efficiency of a photocatalyst is strongly affected by the number of active sites and the photoabsorption ability of the catalyst used. ${ }^{31}$ Adequate catalyst loading increases the generation rate of $\mathrm{e}^{-} / \mathrm{h}^{+}$pairs; hence, we observe the formation of $\cdot \mathrm{OH}$ for enhancing photodegradation and the formation of holes for enhancing mineralization. However, an excess dosage of the catalyst decreases light penetration via the shielding effect of suspended parti$\operatorname{cles}^{32,33}$ and thereby reduces the degradation and mineralization rates. Although the $\mathrm{O}_{3} / \mathrm{H}_{2} \mathrm{O}_{2}+\mathrm{BiPO}_{4} / \mathrm{UV}$ synergy technique exhibits a synergistic effect between $\mathrm{H}_{2} \mathrm{O}_{2}$ and $\mathrm{BiPO}_{4}$, it still cannot avoid the shielding effect. Excess $\mathrm{BiPO}_{4}$ reduces the incident light intensity by reflection despite the large number of active sites present.

\subsection{Mineralization mechanism of thiourea}

To elucidate the degradation pathways of thiourea by the $\mathrm{O}_{3} /$ $\mathrm{H}_{2} \mathrm{O}_{2}+\mathrm{BiPO}_{4} / \mathrm{UV}$ synergy technique, the reaction intermediates were detected by UPLC-IM-QTOF-MS (ESI, Fig. S4 $\dagger$ ); four compounds were identified with peaks of $\mathrm{m} / z 107$ and $\mathrm{m} / z 126$ after $\mathrm{O}_{3} / \mathrm{H}_{2} \mathrm{O}_{2}$ treatment as well as $m / z 102$ and $m / z 74$ after $\mathrm{BiPO}_{4} / \mathrm{UV}$ treatment. Product 1 was identified as thiourea dioxide with $\mathrm{m} / \mathrm{z} 107$, whereas product 2 was identified as melamine with $m / z$ 126. Besides, after the treatment of $\mathrm{BiPO}_{4} /$ UV, product 3 was identified as biuret with $\mathrm{m} / \mathrm{z} 102$.

Based on the analytical intermediates mentioned above, the transformation pathway of thiourea by the $\mathrm{O}_{3} / \mathrm{H}_{2} \mathrm{O}_{2}+\mathrm{BiPO}_{4} / \mathrm{UV}$ synergy technique is illustrated in Fig. 9. The first step of the $\mathrm{O}_{3} /$ $\mathrm{H}_{2} \mathrm{O}_{2}$ treatment mainly contributed to thiourea degradation by hydroxyl radicals together with direct oxidation by hydrogen peroxide and ozone. Thiourea was converted to thiourea dioxide and melamine. We predicted that with further oxidation of hydroxyl radicals, an unstable intermediate was generated and polymerized into melamine immediately.

The mechanism of hydroxyl radicals' oxidation mainly occurred via the following two steps: first, the addition to unsaturated carbon; second, hydrogen abstraction from saturated carbon. ${ }^{34,35}$ According to this, hydroxyl radicals were weak in melamine mineralization. However, the treatment of $\mathrm{BiPO}_{4} /$ UV after $\mathrm{O}_{3} / \mathrm{H}_{2} \mathrm{O}_{2}$ not only increased the amount of hydroxyl

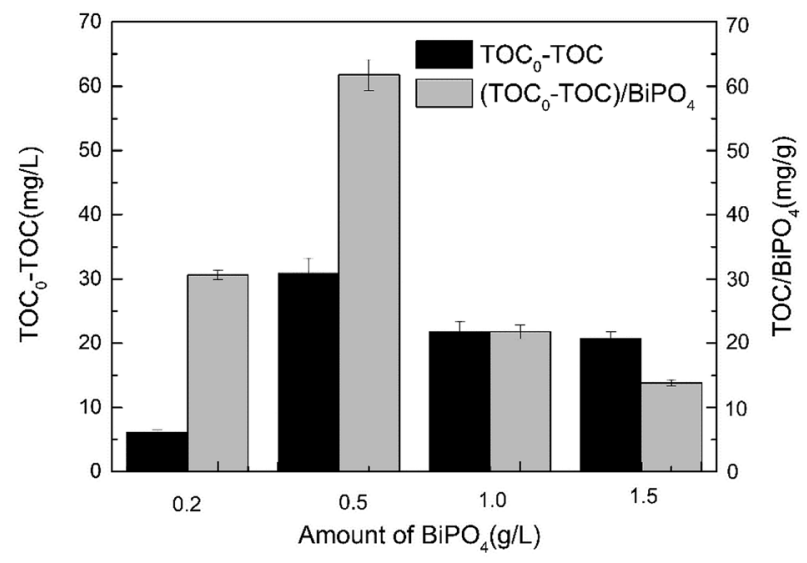

Fig. $8 \mathrm{TOC}$ removal amount and $\left(\mathrm{TOC}_{0}-\mathrm{TOC}\right) / \mathrm{BiPO}_{4}$ ratio in the post-treatment process. The TOC amount after pre-treatment was $174.5 \mathrm{mg} \mathrm{L}^{-1}, \mathrm{H}_{2} \mathrm{O}_{2}$ residue was $71.45 \mathrm{mg} \mathrm{L}^{-1}$, and $U V$ intensity was $4.73 \mathrm{~mW} \mathrm{~cm}^{-2}$. 


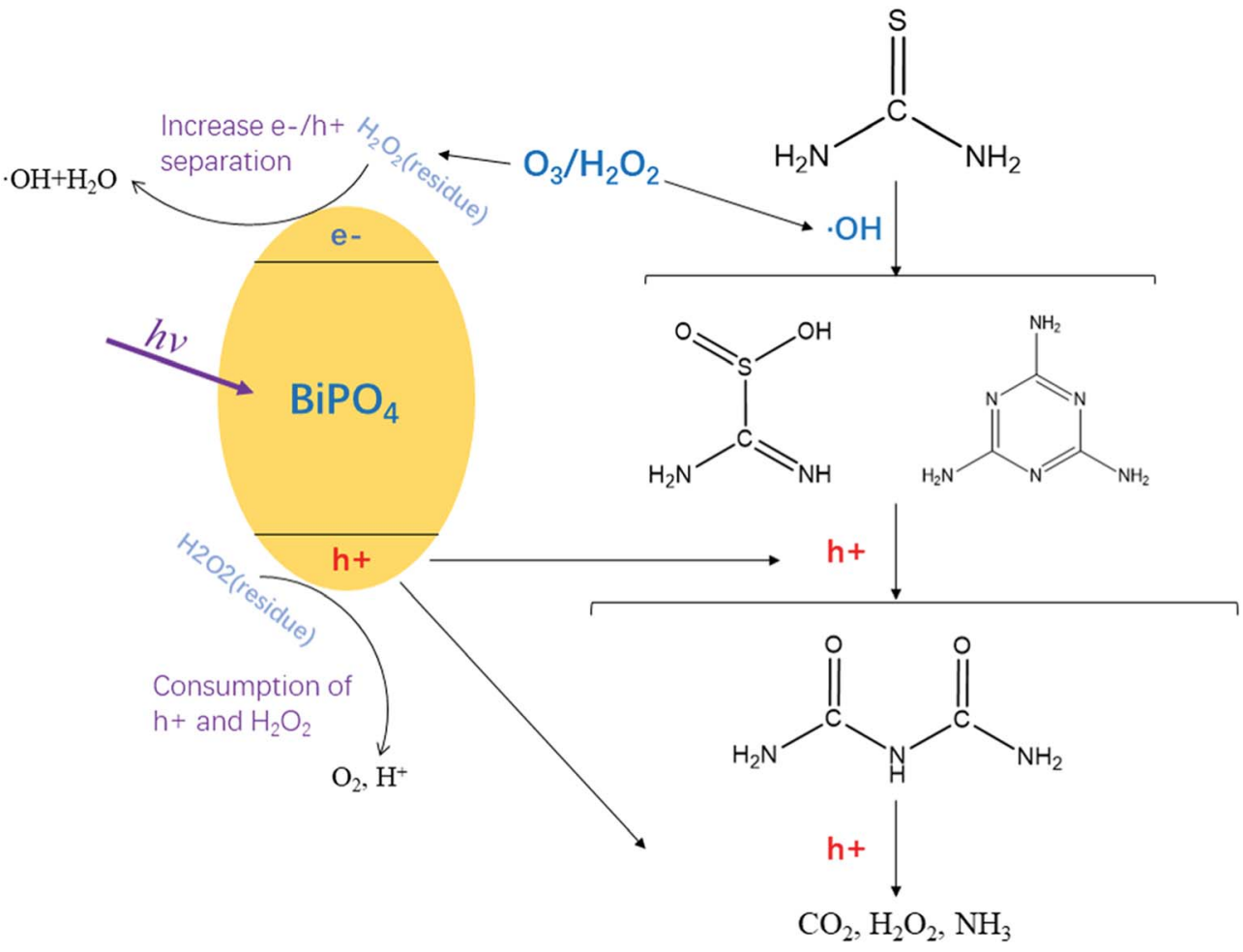

Fig. 9 Prediction of mineralization pathway of thiourea by the $\mathrm{O}_{3} / \mathrm{H}_{2} \mathrm{O}_{2}+\mathrm{BiPO} / \mathrm{UV}$ synergy technique.

radicals, but also introduced the process of hole mineralization. Thus, after the first step of $\mathrm{O}_{3} / \mathrm{H}_{2} \mathrm{O}_{2}, \mathrm{BiPO}_{4} / \mathrm{UV}$ served as the second step to generate holes that carried out the electron transfer oxidation ${ }^{36}$ so that melamine and thiourea dioxide can be further transformed into biuret and then mineralized into $\mathrm{H}_{2} \mathrm{O}$ and $\mathrm{CO}_{2}$. In addition, the $\mathrm{H}_{2} \mathrm{O}_{2}$ residues from $\mathrm{O}_{3} / \mathrm{H}_{2} \mathrm{O}_{2}$ not only increased the separation of $\mathrm{e}^{-} / \mathrm{h}^{+}$but also induced $\cdot \mathrm{OH}$ generation through the reaction between $\mathrm{e}^{-}$and $\mathrm{H}_{2} \mathrm{O}_{2}$; thus, more $\cdot \mathrm{OH}$ species could be generated, which contributed to acceleration of thiourea degradation and mineralization. No thiourea was detected after treatment with the $\mathrm{O}_{3} / \mathrm{H}_{2} \mathrm{O}_{2}+\mathrm{BiPO}_{4} /$ UV synergy technique, and it was transformed into substances introduced before without biotoxicity, which can be further treated by biological methods in a municipal wastewater treatment plant.

\section{Conclusions}

TOC removal, $\mathrm{H}_{2} \mathrm{O}_{2}$ utilization and the transformation pathway of thiourea by the newly invented $\mathrm{O}_{3} / \mathrm{H}_{2} \mathrm{O}_{2}+\mathrm{BiPO}_{4} / \mathrm{UV}$ synergy technique was investigated in this study. Higher mineralization and degradation efficiency of thiourea was attained compared with that of $\mathrm{O}_{3} / \mathrm{H}_{2} \mathrm{O}_{2}$ and $\mathrm{BiPO}_{4} / \mathrm{UV} / \mathrm{H}_{2} \mathrm{O}_{2}$ single-processes and $\mathrm{O}_{3} / \mathrm{H}_{2} \mathrm{O}_{2}+\mathrm{UV}$ process. Thiourea could be completely transformed into substances without biotoxicity. The synergy between $\mathrm{H}_{2} \mathrm{O}_{2}$ and $\mathrm{BiPO}_{4}$ improved the TOC removal and also the utilization of residual $\mathrm{H}_{2} \mathrm{O}_{2}$ left from the $\mathrm{O}_{3} / \mathrm{H}_{2} \mathrm{O}_{2}$ treatment. $\mathrm{H}_{2} \mathrm{O}_{2}$ captured $\mathrm{e}^{-}$on $\mathrm{BiPO}_{4}$, which increased the separation of $\mathrm{e}^{-}$and $\mathrm{h}^{+}$and generated more $\cdot \mathrm{OH}$ in a shorter period. The amount of added $\mathrm{H}_{2} \mathrm{O}_{2}$ influenced both $\mathrm{O}_{3} / \mathrm{H}_{2} \mathrm{O}_{2}$ and $\mathrm{BiPO}_{4} / \mathrm{UV}$ steps, especially $\mathrm{BiPO}_{4} / \mathrm{UV}$, because the addition of excess $\mathrm{H}_{2} \mathrm{O}_{2}$ tended to generate more residual $\mathrm{H}_{2} \mathrm{O}_{2}$, which influenced the synergy between $\mathrm{H}_{2} \mathrm{O}_{2}$ and $\mathrm{BiPO}_{4}$ and decreased the amount of TOC removal. Excessive catalyst loading showed a negative effect on the mineralization efficiency. $\mathrm{O}_{3} / \mathrm{H}_{2} \mathrm{O}_{2}$ mainly degraded thiourea into thiourea dioxide and melamine by $\cdot \mathrm{OH}$, and $\mathrm{BiPO}_{4} / \mathrm{UV}$ degraded them into biuret and methyl carbamate, followed by their further mineralization into $\mathrm{CO}_{2}$ and $\mathrm{H}_{2} \mathrm{O}$.

\section{Conflicts of interest}

The authors have no conflicts of interest to declare.

\section{Acknowledgements}

We greatly acknowledge the financial support from the National Science and Technology Major Projects of Water Pollution Control and Management of China (2014ZX07206001).

\section{References}

1 P. Manivel, K. Prabakaran, V. Krishnakumar, F. R. N. Khan and T. Maiyalagan, Ind. Eng. Chem. Res., 2014, 25, 395-402.

2 R. S. Upadhayaya, G. M. Kulkarni, N. R. Vasireddy, J. K. Vandavasi, S. S. Dixit, V. Sharma and J. Chattopadhyaya, Bioorg. Med. Chem., 2009, 17, 4681-4692.

3 C. Kannan, P. Aditi and B. Zwanenburg, Crop Prot., 2015, 70, 92-98. 
4 G. Vinithra, S. Suganya and S. Velmathi, Tetrahedron Lett., 2013, 54, 5612-5615.

5 L. Zhou, X. Hu and S. Wu, Surf. Coat. Technol., 2013, 228, S171-S174.

6 A. Korhonen, K. Hemminki and H. Vainio, Basic Clin. Pharmacol. Toxicol., 2010, 51, 38-44.

7 G. Mendoza, A. I. Álvarez, M. M. Pulido, A. J. Molina, G. Merino, R. Real, P. Fernandes and J. G. Prieto, Carbohydr. Res., 2007, 342, 96-102.

8 S. Dales and W. S. Hoar, Can. J. Zool., 2011, 32, 244-251.

9 S. A. Khan, N. Singh and K. Saleem, Eur. J. Med. Chem., 2008, 43, 2272-2277.

10 A. Y. Lin, S. C. Panchangam, C. Chang, P. K. A. Hong and H. Hsueh, J. Hazard. Mater., 2012, 243, 272-277.

11 S. Popiel, T. Nalepa, D. Dzierżak, R. Stankiewicz and Z. Witkiewicz, J. Hazard. Mater., 2009, 164, 1364-1371.

12 J. J. Wu, M. Muruganandham and S. H. Chen, J. Hazard. Mater., 2007, 149, 218-225.

13 S. Esplugas, J. Gimenez, S. Contreras, E. Pascual and M. Rodriguez, Water Res., 2002, 36, 1034-1042.

14 H. Zangeneh, A. A. L. Zinatizadeh and M. Feizy, J. Ind. Eng. Chem., 2014, 20, 1453-1461.

15 T. Wu and J. D. Englehardt, Environ. Sci. Technol., 2012, 46, 2291-2298.

16 Y. Lee, D. Gerrity, M. Lee, S. Gamage, A. Pisarenko, R. A. Trenholm, S. Canonica, S. A. Snyder and U. von Gunten, Environ. Sci. Technol., 2016, 50, 3809-3819.

17 J. A. Zazo, J. A. Casas, A. F. Mohedano, M. A. Gilarranz and J. J. Rodríguez, Environ. Sci. Technol., 2005, 39, 9295-9302.

18 C. Pan and Y. Zhu, Environ. Sci. Technol., 2010, 44, 55705574.

19 C. Pan and Y. Zhu, Catal. Sci. Technol., 2015, 5, 371-383.

20 Y. Liu, Y. Zhu, J. Xu, X. Bai, R. Zong and Y. Zhu, Appl. Catal., $B$, 2013, 142-143, 561-567.
21 Y. Zhu, Y. Liu, Y. Lu, H. Wang, Q. Ling and Y. Zhu, Acta Phys.Chim. Sin., 2013, 576-584.

22 R. M. Sellers, Analyst, 1980, 105, 950.

23 H. Christensen, K. Sehested and H. Corfitzen, J. Phys. Chem., 1982, 86.

24 M. F. Kabir, E. Vaisman, C. H. Langford and A. Kantzas, Chem. Eng. J., 2006, 118, 207-212.

25 M. Tokumura, A. Ohta, H. T. Znad and Y. Kawase, Water Res., 2006, 40, 3775-3784.

26 S. Haji, B. Benstaali and N. Al-Bastaki, Chem. Eng. J., 2011, 168, 134-139.

27 E. S. Elmolla and M. Chaudhuri, Desalination, 2010, 252, 4652.

28 V. Auguliaro, E. Davì, L. Palmisano, M. Schiavello and A. Sclafani, Appl. Catal., 1990, 65, 101-116.

29 C. Chiou, C. Wu and R. Juang, Chem. Eng. J., 2008, 139, 322329.

30 Y. Zhang, R. Selvaraj, M. Sillanpää, Y. Kim and C. Tai, Chem. Eng. J., 2014, 245, 117-123.

31 S. Lathasree, A. N. Rao, B. SivaSankar, V. Sadasivam and K. Rengaraj, J. Mol. Catal. A: Chem., 2004, 223, 101-105.

32 A. Burns, W. Li, C. Baker and S. I. Shah, MRS Proceedings, 2001, 703.

33 A. Sobczyński, Ł. Duczmal and W. Zmudziński, J. Mol. Catal. A: Chem., 2004, 213, 225-230.

34 J. A. Khan, X. He, N. S. Shah, H. M. Khan, E. Hapeshi, D. Fatta-Kassinos and D. D. Dionysiou, Chem. Eng. J., 2014, 252, 393-403.

35 T. Olmez-Hanci and I. Arslan-Alaton, Chem. Eng. J., 2013, 224, 10-16.

36 A. Y. Ahmed, T. A. Kandiel, I. Ivanova and D. Bahnemann, Appl. Surf. Sci., 2014, 319, 44-49. 